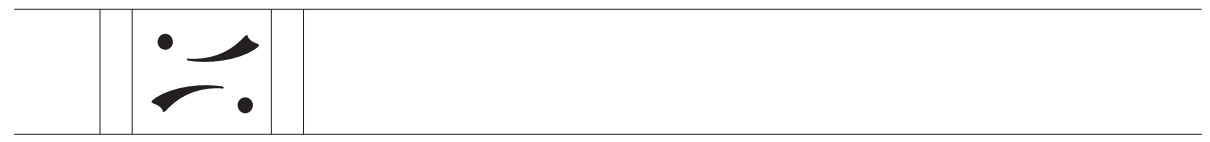

\title{
5. The Scandal of the Irrationality of Academia
}

\author{
Nicholas MaXwell \\ University College London
}

Abstract: Academic inquiry, in devoting itself primarily to the pursuit of knowledge, is profoundly and damagingly irrational, in a wholesale, structural fashion, when judged from the standpoint of helping to promote human welfare. Judged from this standpoint, academic inquiry devoted to the pursuit of knowledge violates three of the four most elementary rules of rational problem-solving conceivable. Above all, it fails to give intellectual priority to the tasks of (1) articulating problems of living, including global problems, and (2) proposing and critically assessing possible solutions-possible social actions. This gross, structural irrationality of academic inquiry stems from blunders of the 18th century French Enlightenment. The philosophes had the brilliant idea of learning from scientific progress how to achieve social progress towards an enlightened world, but in implementing this idea they made three disastrous blunders. They got the nature of the progress-achieving methods of science wrong; they failed to generalize these methods properly; and most disastrously, they applied these methods to acquiring knowledge about society, and not directly to solving social problems. These blunders are still inherent in academia today, with dire consequences for the state of the world. All this has been pointed out prominently many times since 1976, but has been ignored.

Keywords: irrationality of academia; the Enlightenment; global problems; scientific method; academic reform; social progress

For over 40 years I have argued that academic inquiry, as at present conducted by universities around the world, is profoundly and damagingly irrational when judged from the standpoint of helping to promote human welfare. In

(C) 2019 Nicholas Maxwell - http://doi.org/10.3726/ptihe.2019.01.06 - The online edition of this publication is available open access. Except where otherwise noted, content can be used under the terms of the Creative Commons Attribution 4.0 International License (CC-BY 4.0). For details go to http://creativecommons.org/licenses/by/4.0/ 
book after book, paper after paper, lecture after lecture, ${ }^{1}$ I have spelled out what is wrong, what needs to be done to put matters right, and why it is a matter of such supreme importance that this be done. ${ }^{2}$

My 45-year campaign to get a hearing for my argument has been met with almost universal indifference. My books receive glowing reviews. ${ }^{3} \mathrm{My}$

1 Twelve books, 27 chapters contributed to other books, 71 papers published in scientific and scholarly journals, and lectures given at universities and conferences all over the UK, Europe, and North America. See http://www.ucl.ac.uk/from-knowledgeto-wisdom.

2 See especially Nicholas Maxwell, What's Wrong With Science? Towards a People's Rational Science of Delight and Compassion (Hayes: Bran's Head Books, 1976); From Knowledge to Wisdom: A Revolution in the Aims and Methods of Science (Oxford: Basil Blackwell, 1984); The Comprehensibility of the Universe: A New Conception of Science (Oxford: Oxford University Press, 1998); Is Science Neurotic? (London: Imperial College Press, 2004); From Knowledge to Wisdom: A Revolution for Science and the Humanities, 2nd ed. (London: Pentire Press, 2007a); How Universities can Help Create a Wiser World: The Urgent Need for an Academia Revolution (Exeter: Imprint Academic, 2014); Two Great Problems of Learning: Science and Civilization, https:// philpapers.org/rec/MAXTGP-2; Understanding Scientific Progress (Saint Paul, MN: Paragon House, 2017); In Praise of Natural Philosophy: A Revolution for Thought and Life (Montreal: McGill-Queen's University Press, 2017); Karl Popper, Science and Enlightenment (London: UCL Press, 2017). For summaries of the argument see Nicholas Maxwell, "Science, Reason, Knowledge and Wisdom: A Critique of Specialism," Inquiry 23 (1980): 19-81; "What Kind of Inquiry can Best Help Us Create a Good World?" Science, Technology and Human Values 17 (1992): 205-27; "Can Humanity Learn to become Civilized? The Crisis of Science without Civilization," Journal of Applied Philosophy 17 (2000): 29-44; "From Knowledge to Wisdom: The Need for an Academic Revolution," London Review of Education 5, no. 2 (2007): 97-115; "Arguing for Wisdom in the University: An Intellectual Autobiography," Philosophia 40, no. 4 (2012): 663-704; “Can Universities Save Us from Disaster? On the Horizon, 25, no. 2 (2017): 115-30, https://www.emeraldinsight.com/doi/ abs/10.1108/OTH-04-2016-0019.

3 See especially Christopher Longuet-Higgins, "For Goodness Sake," Nature 312 (1984): 204. See also George F. Kneller, Science as a Human Endeavor (New York: Columbia University Press, 1978), 80-87 and 91; Stewart Richards, "Philosophical Aspects of Science," Annals of Science 42 (1985): 348-49; Ziauddin Sardar, "Lies, Damn Lies ... And a Way of Getting Out of Them," Inquiry (1985): 66-67; Mary Midgley, "Is Wisdom Forgotten?," University Quarterly: Culture, Education and Society 40 (1986): 425-27; Brian Easlea, "Review," Journal of Applied Philosophy 3 (1986): 139-40; Norman Frank Dixon, Our Own Worst Enemy (London: Futura, 1988), 273-74; Noretta Koertge, "Review," Isis 80, no. I (1989): 146-47; John Hendry, "Review," British Journal for the History of Science 22 (1989): 246-47; Anjan Chakravartty, "Review," Times Higher Education Supplement (1999): 24; Niall Shanks, "Review," Metascience 9 (2000): 294-98; John Jamieson Carswell Smart, "Review," British Journal for the Philosophy of Science 51 (2000): 907-11; Marvin Harris, Cultural Materialism (London: Vintage, 2001), 25-26; Sherrilyn Roush, 
lectures are acclaimed. A scattering of scientists and scholars around the world support my claim. But in general what I have to say is ignored-by my fellow philosophers, by academics generally, by educationalists, by those in charge of universities, by the media, and by the public.

And yet the structural irrationality that I have identified in academia as at present conducted has vast and very seriously damaging consequences. It puts the very future of humanity at risk. It is this unacknowledged structural irrationality in our institutions of inquiry, more than any other factor, that undermines our efforts to solve the grave global problems of the Anthropocene-this new geological period we find ourselves in, in which we human beings have such a profound and detrimental impact on our world. There could hardly be anything more important, as far as the long-term welfare of humanity is concerned, than to get clear what the intellectual defects of academic inquiry are, and then to put them right. Despite that, my attempts to raise the issue for discussion have, so far, been greeted with little more interest than a universal yawn.

Academics, confined within their specialities, are not prepared to look at academic inquiry as a whole; if they do, they tend to take the view that nothing can be done about it. There is no such thing as "the philosophy of inquiry", concerned with the question of what the basic aims and methods of academic inquiry ought to be. Vice chancellors and ministers of education look at universities from a bureaucratic and narrowly political and economic standpoint. The general public tends to interpret "academic" to mean "irrelevant", and would not dream of thinking that the structural irrationality of academia is a serious issue. The gross structural irrationality of academia threatens our future-and no one is interested. ${ }^{4}$

\footnotetext{
"Review," The Philosophical Review 110 (2001): 85-87; Fred Muller, "Maxwell's Lonely War," Studies in History and Philosophy of Modern Physics 35 (2004): 109-10 and 117; Mathew Iredale, "Review," The Philosopher's Magazine 31 (2005): 86-87; Leemon McHenry, "Review," Review of Metaphysics 59, no. 3 (2006): 657-59; Margret Grebowicz, "Review," Metascience 15 (2006): 141-44; Joseph Davidow, "Review," Learning for Democracy 2 (2006): 78-80; Donald Stanley, "Review," Metapsychology 11, no. 30 (2007). http://metapsychology.mentalhelp.net/poc/ view_doc.php?type=book\&id=3746\&cn=394; Alisdair MacIntyre, "The Very Idea of a University," British Journal of Educational Studies 57, no. 4 (2009): 358; Peeter Müürsepp, "Review," Dialogue and Universalism 2 (2014): 247; Terry Biddington, "Review: In Praise of Natural Philosophy." Metapsychology 21 (2017): 34, http:// metapsychology.mentalhelp.net $/$ poc $/$ view doc.php? type =book\&id=7935\& $\overline{\mathrm{cn}=394}$; David Lorimer, "Aim-Oriented Empiricism," Paradigm Explorer 2017, no. 2 (2017): 43-44.
}

4 Lack of interest might, of course, be due to the hopeless invalidity of my argument, or its inapplicability, somehow, to the real world. But how can this be known if the 
These days of the Anthropocene it is quite widely appreciated that we face grave global problems-problems which threaten our future if not soon resolved effectively and responsibly. These problems include: rapid population growth; the spread of modern armaments, conventional, chemical, and nuclear; the lethal character of modern war and terrorism; destruction of natural habitats and rapid extinction of species; gross inequalities of wealth and power around the globe; threats to democracy helped along by the internet; pollution of Earth, sea, and air; and perhaps most serious of all, the impending disasters of climate change.

What is not so widely appreciated is that all these problems have been made possible by modern science and technology. Science and technology have, of course, been of great benefit to humanity in a multitude of ways. They have made the modern world possible. But in making possible modern industry and agriculture, modern armaments, modern medicine and hygiene, they have also led to the global problems so characteristic of our Anthropocene age: population growth, habitat destruction, species extinction, lethal warfare, pollution, and global warming.

Some blame science for our problems, but that misses the point. What has gone wrong is the pursuit of science and technology in a way that is dissociated from a more fundamental concern with our problems of living, including our global problems, and how best to solve them. We have failed to develop a kind of academic inquiry centrally and fundamentally concerned to help humanity learn how to resolve conflicts and problems of living in increasingly cooperatively rational ways, science being an important but subordinate part of such an academic enterprise. Academia as it exists today, with its emphasis on the pursuit of specialized scientific knowledge is, as I have said, irrational in a structural and profoundly damaging way. It is hardly too much to say that all the bad features of our Anthropocene age have been created by the astonishing intellectual successes of modern science and technology combined with the failure to develop academic inquiry in such a way that it is primarily rationally devoted to helping humanity solve problems of living, including global problems.

argument is not noticed, and subjected to serious scrutiny? In any case, many of those who have read my work are not at all inclined to dismiss it as invalid, irrelevant, or impracticable: see note 3. When my From Knowledge to Wisdom was first published it received many glowing reviews: the one in Nature declared "Maxwell is advocating nothing less than a revolution (based on reason, not on religious or Marxist doctrine) in our intellectual goals and methods of inquiry ... There are altogether too many symptoms of malaise in our science-based society for Nicholas Maxwell's diagnosis to be ignored" (Longuet-Higgins 1984). Unfortunately, my diagnosis and, more important, my proposed prescription have been ignored. If they had not, the world might not be in quite the mess that it is in today. 
The global problems that confront us, engendered by unprecedented powers to act bequeathed to some of us by modern science and technology, are extraordinarily complex, relatively new, and global in their scope. We have to learn how to resolve them. Politics, economics, industry, societies and cultures, individuals, nations, and international bodies, all have to learn how best to go about tackling these immense, intractable problems, integrated as so many are into our whole way of life today on the planet. That in turn requires that we have institutions of learning rationally designed and devoted to the task. It is just that we do not at present have. Instead, what we do have is academic inquiry devoted primarily, and in the first instance, to the pursuit of specialized scientific knowledge. And that, if anything, promises to intensify our problems-for it is the immensely successful pursuit of scientific knowledge dissociated from a more fundamental concern with learning how to tackle problems of living that has led to the creation of our global problems in the first place, and to the persistence of our inability to resolve them.

From the past we have inherited the idea that the proper way for academia to proceed, in order to help promote human welfare, is, first, to acquire knowledge and then apply it to help solve social problems. For this to work, science must acquire authentic, reliable, objective factual knowledge. That in turn requires, so it is held, that science attends only to factors relevant for the assessment of claims to knowledge: evidence, valid argument, logic. Everything else must be excluded from the intellectual domain of science: values, politics, human aspirations, cries of distress, expressions of human suffering, proposals for action-everything required to articulate problems of living and propose and critically assess possible solutions-possible actions. If such matters were allowed to influence science-so it is held-scientific knowledge would degenerate into mere propaganda or ideology, and its human value would be lost. According to this orthodox view, in short, discussion of problems of living and how to solve them must be ruthlessly excluded from science so that science may deliver authentic knowledge, and thus provide genuine help with solving problems of living. In order to solve problems of living, in other words, science must ignore them!

In my work I call this orthodox view, this paradigm for academic inquiry, knowledge-inquiry. ${ }^{5}$ As I have just formulated it, it had greater influence in

5 For a much more detailed exposition of knowledge-inquiry, called "the philosophy of knowledge", see Maxwell, From Knowledge to Wisdom, ch. 2. See also Maxwell, How Universities Can Help Create a Wiser World, 6-10, 20-22; Maxwell, Two Great Problems of Learning, ch. 2, section 3. 
the 1950s, perhaps, than it does today. Nevertheless, the influence of this orthodox paradigm of knowledge-inquiry lingers on. Academia does discuss problems of living, including global problems, and does discuss what can be done to solve them; nevertheless such discussion tends to be pushed to the periphery, and sidelined; it is not central and fundamental to academic inquiry as a whole just because it does not contribute to knowledge. Knowledge-inquiry has not been repudiated in the thoroughgoing way that is required, so that a more rigorous view can be adopted and implemented in its stead.

What is not generally appreciated is that knowledge-inquiry-the basic prescription "first acquire knowledge; then apply it to solve social problems"-violates the most elementary and uncontroversial rules of reason conceivable; it is today this elementary irrationality of science, and of academia more generally, that is so profoundly damaging, stultifying as it does our capacity to anticipate the emergence of global problems, and learn how to tackle them effectively, intelligently, and humanely when they do emerge.

What ought we to mean by "reason" in the current context? The notion we require stipulates that there is a set of general rules, methods, or strategies which, if put into practice, give us, other things being equal, our best chances of solving our problems, achieving our aims. These rules of reason do not guarantee success. They indicate what we should attempt, and do not specify precisely what we should do. They are meta-methods, in that they assume that there is much that we can already do successfully, implementing a multitude of methods in our actions, and they suggest how we can best marshal these already solved problems in order successfully to solve new, as-yet unsolved problems. ${ }^{6}$

Why proceed rationally whatever we may be doing? Because, other things being equal, that gives us our best chance of solving our problems, achieving our aims. The more we depart from reason, the more we undermine our chance of success - of achieving what is genuinely of value.

Four elementary, wholly uncontroversial rules of rational problem solving are:

(1) Articulate and seek to improve the articulation of the basic problem(s) to be solved.

(2) Propose and critically assess alternative possible solutions.

6 For an exposition of rationality along these lines see Maxwell, From Knowledge to Wisdom, 67-70 and 92-94; or Maxwell, From Knowledge to Wisdom (2nd ed.), 79-83 and 105-7. 
(3) When necessary, break up the basic problem to be solved into a number of specialized problems-preliminary, simpler, analogous, subordinate problems-[ to be tackled in accordance with rules (1) and (2)], in an attempt to work gradually towards a solution to the basic problem to be solved.

(4) Inter-connect attempts to solve the basic problem and specialized problems, so that basic problem solving may guide, and be guided by, specialized problem solving.

Any problem-solving enterprise which persistently violates just one of these rules must be seriously irrational, and its capacity to solve problems will be adversely affected as a consequence. Academic inquiry today, as a result of the lingering, pervasive influence of knowledge-inquiry, violates three of these four rules of reason, when viewed from the standpoint of helping to promote human welfare by intellectual and educational means. The irrationality of academia is as serious as that. ${ }^{7}$

To begin with, modern academia puts rule (3) into practice to splendid effect. This is indeed the most striking feature of academia today-the extent to which it is compounded of more and more increasingly specialized disciplines devoted to tackling ever more specialized problems.

Rules (1), (2), and (4) are, however, violated. Granted the basic task is to help promote human welfare, the problems that need to be solved, fundamentally, are invariably problems of living, problems of action. Even where new knowledge and technology are required, as they are in medicine and agriculture, for example, it is always what this knowledge enables us to $d o$ (or refrain from doing) that solves the problem of living, not the knowledge or technology per se. Therefore, in order to put rules (1) and (2) into academic practice we need to:

7 There are those, of course, who celebrate irrationality and deplore reason. Almost always it is not reason that is opposed, but some version of irrationality masquerading as reason. Thus proponents of irrationality may uphold the value of wild imaginative exploration of possibilities under the impression that such an activity is irrational. It is, on the contrary, a vital component to rational problem solving, as depicted here; only an untenable, irrational conception of reason-one which, for example, holds that rational thinking proceeds strictly in accordance with rules-would hold that wild imaginative exploration of possibilities is irrational. Opposition to reason is almost always based on misconceptions as to what reason really is. Indeed, so widespread are misconceptions concerning the nature of reason that most proponents of rationality are actually proponents of some species of irrationality dressed up as reason: see note 15 . 
$\left(1^{*}\right)$ Articulate our problems of living, and improve the articulation of these problems;

$\left(2^{*}\right)$ Propose and critically assess possible solutions-possible actions, policies, political programmes, ways of living, new or modified institutions, philosophies of life.

But $\left(1^{*}\right)$ and $\left(2^{*}\right)$ cannot proceed within the framework of knowledge-inquiry, certainly not as the central, fundamental intellectual tasks of inquiry, because in implementing these rules in this way, no contribution is made to knowledge. In proposing a policy, in advocating a political, economic, or legal action (a new piece of legislation, a new institutional arrangement) one is not contributing to factual knowledge.

Once rules (1) and (2) are not implemented, rule (4) cannot be implemented either. Three of the four most basic rules of reason are violated.

Academia today, because of the lingering influence of knowledge-inquiry, persistently violates three of the four most elementary, basic rules of reason conceivable in a wholesale, structural fashion. And as a direct consequence, academia cannot do what it most needs to do. It cannot help humanity anticipate new global problems, work out what needs to be done to resolve them in an effective way before they become too serious, and help humanity develop the political muscle needed for this to be done. In so far as academia continues to be affected by the lingering influence of knowledge-inquiry, these vital intellectual activities cannot be engaged in as the central and fundamental intellectual tasks. That is indeed the case of academia today. The long-standing irrationality of our institutions of learning, world-wide, has a large measure of responsibility, in other words, for our inability to anticipate new global problems and deal with them before they become too serious - and rapidly increase our capacity to deal with the problems effectively if they do become serious. The result is the world as it is today. ${ }^{8}$

8 The damaging humanitarian repercussions of the gross structural irrationality of knowledge-inquiry (or the philosophy of knowledge) are discussed in detail in Maxwell, From Knowledge to Wisdom; Is Science Neurotic?; From Knowledge to Wisdom (2nd ed.); How Universities Can Help Create a Wiser World; Two Great Problems of Learning; In Praise of Natural Philosophy. See also Maxwell, "Science, Reason, Knowledge and Wisdom"; "What Kind of Inquiry Can Best Help Us Create a Good World?"; "Can Humanity Learn to become Civilized?”; "From Knowledge to Wisdom"; "Arguing for Wisdom in the University"; "Can Universities Save Us from Disaster?”. 
Those wedded to knowledge-inquiry may object that knowledge must first be acquired before problems of living can be tackled rationally. There are a number of things wrong with this objection. First, many conflicts and problems of living require new deeds, new policies, new ideas for action, for their resolution, not new knowledge. Second, we cannot know what kind of new knowledge we need to try to develop unless we have at least a preliminary idea as to what our problems are, and what we propose to do about them. A slight change in the way we formulate a problem can change dramatically the kind of knowledge we need to try to acquire. Construe the basic problem of medicine to be to cure disease, and the kind of knowledge we need to try to acquire is very different from that needed if we modify the basic problem slightly so that it becomes to prevent disease. Third, even when new knowledge is required, it must always be vital to assess human actions that employ the knowledge from the standpoint of their capacity to solve the problem of living.

What needs to be done to cure academia of its damaging irrationality? The answer is straightforward: academia needs to be changed just enough to ensure that all four basic rules of reason are put into academic practice. The outcome would be a new kind of academic enterprise that I call wisdom-inquiry. Within the context of this new kind of inquiry, social science and the humanities cease to be, fundamentally, devoted to the pursuit of knowledge, and instead take up the fundamental intellectual tasks of articulating problems of living, and proposing and critically assessing possible solutions-possible actions, policies, etc. Their basic task is to promote the cooperatively rational tackling of problems of living in the diverse contexts of the social world. ${ }^{9}$ Below I give a more detailed account of what needs to be changed to transform irrational knowledge-inquiry into rigorous wisdom-inquiry.

When, how, and why did academic inquiry, as it exists today, come to be so profoundly and damagingly irrational in this structural fashion? The answer to this question provides us with a second argument for the urgent need to transform academia, an argument which strengthens and deepens the one just given.

9 For more detailed expositions of, and arguments for, wisdom-inquiry (or "the philosophy of wisdom") see Maxwell, From Knowledge to Wisdom, especially chs. 4 and 5. See also Maxwell, Is Science Neurotic?; From Knowledge to Wisdom (2nd ed.); How Universities Can Help Create a Wiser World; Two Great Problems of Learning; "From Knowledge to Wisdom"; "Arguing for Wisdom in the University"; "Can Universities Save Us from Disaster?”. 
The answer to the question takes us back to the 18th-century Enlightenment. The philosophes of the French Enlightenment, Voltaire, Diderot, and the rest, had the magnificent idea that it might be possible to learn from scientific progress how to achieve social progress towards an enlightened world. They did what they could to put this idea into practice in their lives, and had an immense impact on subsequent history as a result. ${ }^{10}$ But in developing the idea intellectually, they made a series of blunders, and it is these blunders, still built into academia, that we suffer from today.

In order to develop the Enlightenment idea, three steps need to be got right.

(I) The progress-achieving methods of natural science must be correctly characterized.

(II) These methods must be appropriately generalized so that they become potentially fruitfully applicable to any worthwhile, problematic human endeavour, and not just to science.

(III) These generalized, progress-achieving methods must then be got into the fabric of personal and social life, into our other social endeavours besides science, and above all into the endeavour to make progress towards as good a world as possible.

The philosophes got all three steps wrong. First, they mistakenly held that the methods of natural science consist in assessing claims to knowledge impartially and exclusively by means of evidence. Secondly, they failed to generalize these methods to become a conception of rationality fruitfully applicable to any worthwhile, problematic human endeavour, and not just applicable to the pursuit of knowledge. And thirdly, and most disastrously, they applied rationality, derived from the progress-achieving methods of natural science, not directly to social life, to the endeavour to make social progress towards a good, enlightened world, but instead to the task merely of improving knowledge about the social world. It is this third, monumental blunder that led to the development of knowledge-inquiry, from which we now suffer. It led the philosophes to set about creating the social sciences: economics, psychology, sociology, and the rest. These were developed throughout the 19th century, often outside universities, by J. S. Mill, Karl Marx, Max Weber, and others, and were built into universities with the creation of departments of social science in the early 20 th century. The outcome is what we have today: academic

10 See Peter Gay, The Enlightenment: An Interpretation (London: Wildwood House, 1973); Jonathan Israel, Democratic Enlightenment (Oxford: Oxford University Press, 2013). 
inquiry devoted intellectually to the pursuit of knowledge, as far as both the natural and the social worlds are concerned. ${ }^{11}$

It is not perhaps such a scandal that the philosophes made their three blunders in developing the profoundly important basic Enlightenment idea of learning from scientific progress how to make social progress towards an enlightened world. The dreadful scandal is, rather, that these three blunders are still with us today, still built into science, and into academia more generally, nearly three centuries later-and hardly anyone notices. Even worse, perhaps, when the scandal is noticed, hardly anyone shows any interest.

Despite its intellectual and humanitarian failings, academic inquiry as it exists today arose out of the attempt to create a kind of inquiry which would embody the great Enlightenment idea-a kind of inquiry rationally devoted to helping humanity make progress towards a good world. It fails in this task because it embodies the three Enlightenment blunders. All this ought to be regarded as very good news. In order to create institutions of learning that really can help humanity make progress towards a better world, there is no need to begin from scratch as it were. All we need to do is transform the academic status quo just sufficiently to ensure that all three Enlightenment blunders are put right. Let us take the three steps of the basic Enlightenment idea in turn.

Step (I): the progress-achieving methods of science. The scientific community today still upholds the Enlightenment view that the basic aim of science is truth, the basic method being to assess claims to knowledge by means of evidence alone. This orthodox view of standard empiricism (as I have called it) is, however, untenable. In physics, a new theory, in order to be accepted, must be (a) sufficiently empirically successful and (b) sufficiently unified. ${ }^{12}$ Endlessly many disunified rival theories can always be concocted to fit the evidence even better than the accepted theory, but these never get considered for a moment. This persistent rejection of empirically more successful, disunified rivals means that physics accepts implicitly a metaphysical (i.e. untestable) thesis about the world, independent of (or even

11 See James Farganis, ed., Readings in Social Theory: The Classic Tradition to PostModernism (New York: McGraw-Hill, 1993), introduction; Friedrich August Hayek, The Counter-Revolution of Science (Indianapolis, IN: LibertyPress, 1979).

12 A physical theory is unified if what it asserts about the world is the same for all the phenomena to which it applies. If a theory makes $N$ distinct assertions for $N$ distinct ranges of phenomena, then the theory is disunified to degree N. For unity, we require that $N=1$. For further details see Maxwell, Understanding Scientific Progress, ch. 5 . 


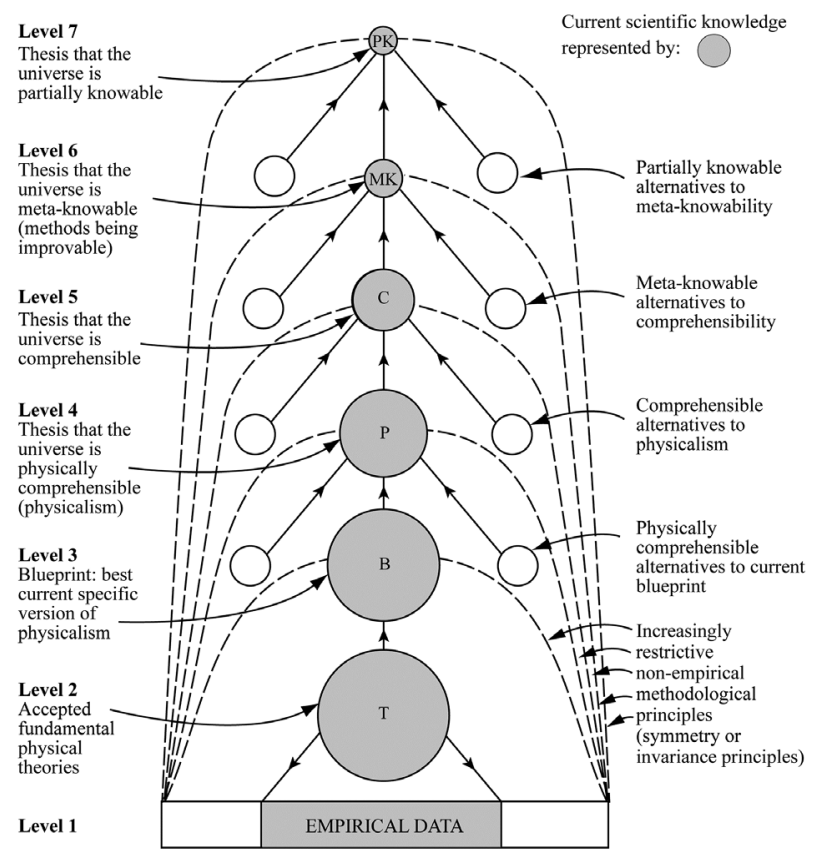

Figure 5.1. Aim-Oriented Empiricism. Source: Nicholas Maxwell, Is Science Neurotic? (London: Imperial College Press, 2004), 19.

against) the evidence, which asserts at least: the universe is such that no seriously disunified theory is true. There is, in other words, some kind of underlying unity in nature.

This implicit metaphysical presupposition is both influential and problematic. It needs to be made explicit so that it can be critically assessed and, we may hope, improved. In order to facilitate its improvement, we need to represent it in the form of a hierarchy of metaphysical assumptions, and associated methods, these assumptions becoming progressively less and less substantial and so more and more likely to be true, and more nearly such that their truth is required for science to be possible at all, as we go up the hierarchy (see Figure 5.1). The assumption at the top, at level 7, is: the universe is such that we can acquire some knowledge of our immediate circumstances sufficient to make life possible. We will never want to reject that conjectural assumption, even if we have no reason to hold it to be true. From level 6 to level 2, that thesis is accepted which best accords with the thesis above. The thesis at level 3 is chosen to do the best justice to the most empirically progressive research programme of theoretical physics. 
All this may be reformulated in terms of aims. The aim of theoretical physics is not truth per se; rather, it is truth presupposed to be explanatoryexplanatory truth, in other words. Because this aim is profoundly problematic, we need to represent it in the form of a hierarchy of aims, and associated methods, aims becoming less and less specific and problematic, as we go up the hierarchy.

As physics advances, and knowledge improves, aims and methods, low down in the hierarchy, improve as well. There is something like positive feedback between improving scientific knowledge, and improving aims and methods-improving knowledge about how to improve knowledge. According to this conception of science, which I have called aim-oriented empiricism, this positive feedback feature is the nub of scientific rationality. It helps explain the explosive growth in scientific knowledge and understanding. For, even though most scientists pay at least lip service to the orthodox standard empiricist view that evidence alone decides what theories are accepted and rejected, physics in practice, in a somewhat implicit way, has put something like aim-oriented empiricist view into practice. If it had not done, we would still be stuck with Aristotelian science. ${ }^{13}$

In addition to metaphysical assumptions, the aims of science have inherent in them profoundly problematic assumptions about values and politics, the social uses of science. Scientific rigour requires that these problematic value and political assumptions be acknowledged within science too, so that they can be critically assessed and, we may hope, improved, within the context of aim-oriented empiricism. Orthodox standard empiricism, however, holds that the basic intellectual aim of science is the fixed one of truth; this does not permit sustained discussion of problematic assumptions concerning metaphysics, values, and politics as an integral part of science itself. In the interests of a misconceived conception of scientific rationality, the rationality of science is undermined. ${ }^{14}$

Correcting the first step, then, involves rejecting the orthodox standard empiricist conception of science that holds that, in the end, evidence alone decides what theories are accepted; it involves adopting and implementing aim-oriented empiricism instead as constituting the correct progress-achieving methods of science.

13 For more detailed expositions of, and arguments for, aim-oriented empiricism see Maxwell, From Knowledge to Wisdom, chs. 5 and 9; The Comprehensibility of the Universe; Is Science Neurotic?, chs. 1 and 2 and appendix; From Knowledge to Wisdom (2nd ed.), chs. 5, 9 and 14; Understanding Scientific Progress; In Praise of Natural Philosophy; Karl Popper, Science and Enlightenment, chs. 2-7.

14 See works referred to in note 13. 
Step (II) involves generalizing aim-oriented empiricism to form aimoriented rationality, a conception of rationality especially fruitful when aims are problematic or misrepresented, as they often are. Aim-oriented rationality requires us to represent problematic aims in the form of a hierarchy of aims, and associated methods, on analogy with aim-oriented empiricism, so that we create a framework of relatively unproblematic aims and methods, high up in the hierarchy, within which much more problematic and contested aims, and associated methods, may be improved as we seek to resolve conflicts, and act. ${ }^{15}$

Step (III) consists in the vital, momentous, and long-term task of getting aim-oriented rationality adopted and implemented in personal and social life. Progress-achieving methods, which have proved to be so astonishingly successful in natural science, need to be got into all our other worthwhile social and institutional endeavours with problematic aims: government, industry, agriculture, the economy, finance, international relations, the media, the law, education, marriage, personal life. The aim is to get into social and political life something of the progressive success achieved so strikingly by natural science-so that our global society may make progress towards a better, wiser, more enlightened world.

The proper, primary task of social inquiry and the humanities is to work out how this is to be done, in a multitude of social contexts, and help people do it. This means that social inquiry is not primarily social science; it is not primarily devoted to the pursuit of knowledge of social phenomena: rather, the various branches of social inquiry and the humanities have two basic tasks. First, they need to do what I indicated above, promote increasingly cooperatively rational tackling of problems of living in the social world. Second, they have the task of helping humanity put aim-oriented rationality into practice in personal and social life. Social inquiry needs to be pursued, and conceived of, as social methodology or social philosophy. What philosophy of science is to science within the framework of aim-oriented empiricism, namely that part of the scientific endeavour which seeks to articulate and improve the aims and methods of science, so social inquiry and the humanities are to the social

15 Any conception of reason which leads us astray systematically cannot be valid. All conceptions of reason which are about means only, and contain no help with improving aims will lead us astray systematically when aims are problematic (and we pursue aims not in our best interests). Thus, all such conceptions of reason that are about means only-as all orthodox conceptions of reason are-are untenable. Aim-oriented rationality is the only candidate for authentic reason because it alone contains within it provision for the improvement of problematic aims. 
world. Their task is to articulate and help improve problematic aims and associated methods of diverse social endeavours. ${ }^{16}$

Aim-oriented rationality is especially relevant when it comes to the task of making progress towards a good, civilized world (see Figure 5.2). The aim of this endeavour is inherently and profoundly problematic for all sorts of more or less obvious reasons. Here, above all, we need to try to improve our aims and methods as we proceed. It is vital to implement aim-oriented rationality. Failure to do so accounts for some of the greatest disasters of the 20th century. Utopian ideals and programmes, whether of the far left or right, have promised heaven on Earth but, pursued in a dictatorial fashion, have led to horrors. Stalin's and Hitler's grandiose plans led to the murder of millions. Even saner, more modest, more humane and rational political programmes, based on democratic socialism, liberalism, or free markets and capitalism, but bereft of aim-oriented rationality, seem to have failed us.

The astonishing intellectual success of modern science and technology has made it possible for us to achieve the goals of more people, more industry and agriculture, more wealth, longer lives, more development, housing and roads, more travel, more cars and aeroplanes, more energy production and use, more and more lethal armaments (for defence). These goals have seemed inherently desirable and, in many ways, are desirable. But our successes in achieving these aims have also brought about global warming, war, vast inequalities across the globe, destruction of habitats and extinction of species. All our current global problems are the almost inevitable outcome of our long-term failure to put aim-oriented rationality into practice in life and so actively seek to discover problems associated with our long-term aims, actively explore ways in which problematic aims can be modified in less problematic directions, and at the same time develop the social, the political, economic and industrial muscle able to change what we do, how we live, the technology we develop, so that our aims become less problematic, less destructive in both the short and long term. We have failed even to appreciate the fundamental need to improve aims and methods as the decades go by. Because of the dominance of knowledge-inquiry, academia cannot even entertain the idea that it has, as a basic task, to help humanity learn how to put aim-oriented rationality into practice in all the diverse contexts of social life. Even worse, academia does not put aim-oriented empiricism and aim-oriented rationalism into practice itself. As a result, the mere idea that it is of fundamental importance to put aim-oriented rationality into practice in personal and social life

16 For more detailed expositions of steps (II) and (III) see Maxwell, From Knowledge to Wisdom, chs. 5-11; Is Science Neurotic?; From Knowledge to Wisdom (2nd ed.), chs. 5-13; Two Great Problems of Learning; In Praise of Natural Philosophy, ch. 8. 
is, as yet, all-but unknown. Conventional ideas about rationality are all about means, not about ends, and are not designed to help us improve our ends as we proceed (see note 15). And all this remains true today despite the fact that reasons for adopting and implementing aim-oriented rationality were prominently published at least 34 years ago (Maxwell 1984).

There is another way in which academia dominated by knowledge-inquiry fails humanity. It cannot devote itself to public education about what our problems are, and what we need to do about them. It is vital that we tackle our global problems democratically. But elected governments are not likely to be much more enlightened than electorates. Democracies need electorates to be enlightened about what our problems are, and what we need to do about them; without such enlightenment, democratic governments are unlikely to do what needs to be done to resolve global problems; and there is always the danger that democracies become dysfunctional. Wisdom-inquiry would be actively devoted to acquiring and promoting education about what our problems are, and what we need to do about them; knowledge-inquiry, engaged in the pursuit of specialized knowledge, cannot begin to do what is required.

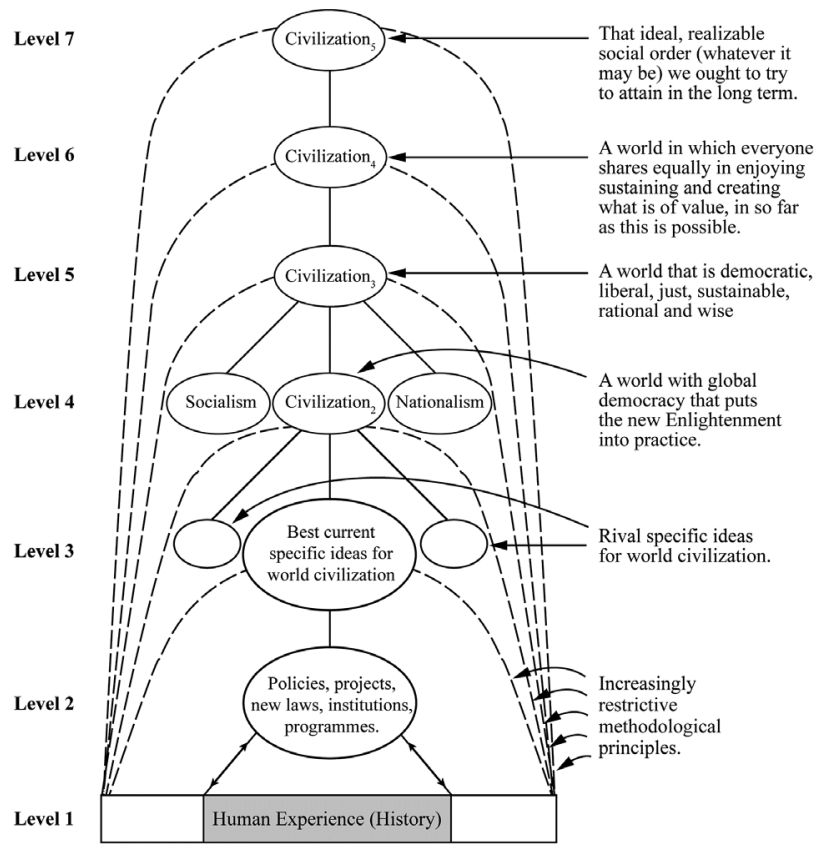

Figure 5.2. Aim-Oriented Rationality Applied to the Task of Creating a Wiser World. Source: Nicholas Maxwell, Is Science Neurotic? London: Imperial College Press, 2004, 96. 
The outcome of implementing all four rules of reason indicated above and, on top of that, correcting the three blunders of the Enlightenment in the ways just indicated would be fully fledged wisdom-inquiry, a kind of academic inquiry very different from what we have at present. The basic task of wisdom-inquiry is to devote reason to the enhancement of wisdom-wisdom being understood to be the desire, the active endeavour, and the capacity to discover and achieve what is desirable and of value in life, both for oneself and for others. Wisdom includes knowledge and understanding but goes beyond them in also including: the desire and active striving for what is of value, the ability to see what is of value, actually and potentially, in the circumstances of life, the ability to experience value, the capacity to help realize what is of value for oneself and others, the capacity to help solve those problems of living that arise in connection with attempts to realize what is of value, the capacity to use and develop knowledge, technology and understanding as needed for the realization of value. Wisdom, like knowledge, can be conceived of not only in personal terms, but also in institutional or social terms. We can thus interpret the basic task of wisdom-inquiry to be to help us develop wiser ways of living, wiser institutions, customs and social relations, a wiser world. Wisdom-inquiry does better justice than knowledge-inquiry to both aspects of inquiry: inquiry pursued for its own sake to help us see, know, and understand ${ }^{17}$; and inquiry pursued for the sake of other goals of value-health, prosperity, peace, democracy, love.

Wisdom-inquiry is a synthesis of traditional rationalism and romanticism, and a radical improvement over both. It incorporates romantic ideals of integrity, having to do with motivational and emotional honesty, honesty about desires and aims; and at the same time it incorporates traditional rationalist ideals of integrity, having to do with respect for objective fact, knowledge, and valid argument. Traditional rationalism takes its inspiration from science and method, romanticism from art, imagination, and passion. Wisdom-inquiry holds art to have a fundamental rational role in inquiry, in revealing what is of value, and unmasking false values; but science, too, is of fundamental importance. What we need, for wisdom, is an interplay of sceptical rationality and emotion, an interplay of mind and heart, "so that we may acquire heartfelt minds and mindful hearts". ${ }^{18}$

17 See, for example, Maxwell, "From Knowledge to Wisdom", 110-12; Two Great Problems of Learning; ch. 4, section 3; In Praise of Natural Philosophy, especially ch. 5.

18 Maxwell, What's Wrong With Science?, 5. There is even a religious, a spiritual dimension to wisdom-inquiry, as I have tried to indicate in Nicholas Maxwell, Cutting God in Half - And Putting the Pieces Together Again: A New Approach to Philosophy (London: Pentire Press, 2010). 
We urgently need an academic revolution, a change of paradigm, from knowledge-inquiry to wisdom-inquiry (as I have repeatedly argued ever since 1976). We need to put all four basic rules of reason into academic practice. And on top of that, we need to correct the three blunders of the Enlightenment. ${ }^{19}$ What, in more detail, would be the consequences of putting these steps towards greater rationality into academic practice? Here is an indication of some of the structural changes involved in transforming knowledge-inquiry into wisdom-inquiry.

1. There needs to be a radical change in the basic aim of academic inquiry. Knowledge-inquiry has two distinct aims: the intellectual one of acquiring knowledge, and the social or humanitarian one of helping to promote human welfare by intellectual, technological, and educational means. Wisdom-inquiry fuses these two aims into one: the intellectual/humanitarian aim of seeking and promoting personal and social wisdom as characterized above.

2. There needs to be a change in the nature of academic problems, so that problems of living are included, as well as problems of knowledge-the former being treated as intellectually more fundamental than the latter.

3. There needs to be a change in the nature of academic ideas, so that proposals for action are included as well as claims to knowledge - the former, again, being treated as intellectually more fundamental than the latter.

19 In the last two decades or so, some changes have taken place in academia which have taken us away from knowledge-inquiry and towards wisdom-inquiry: see Maxwell, From Knowledge to Wisdom, chs. 6, 11 and 12; How Universities Can Help Create a Wiser World, ch. 4. However, as I also make clear in these references, these developments have been piecemeal, muddled, and agonizingly slow; there is still no general awareness in academia of just how far-reaching and damaging the structural irrationality of academic inquiry is, how urgent the need is for radical change. Academics who concern themselves with climate change and other global problems may blame governments, industry, and economics, but rarely see responsibility as lying closer to home, in the dysfunctional character of academia itself. And during the last two decades or so, other changes in academia have taken place which have had the effect of taking us further away from wisdom-inquiry: increased specialization, more precarious employment, greater dependence on the market for funding, even creeping scientific corruption as in phenomena such as "ghost-writing": see http://www.sgr. org.uk/events/universities-sale and Leemon McHenry and Jon Jureidini, "Industry-sponsored Ghostwriting in Clinical Trial Reporting: A Case Study," Accountability in Research: Policies and Quality Assurance 15, no. 3 (2008): 152-67. 
4. There needs to be a change in what constitutes intellectual progress, so that progress-in-ideas-relevant-to-achieving-a-more-civilized-world is included as well as progress in knowledge, the former being indeed intellectually fundamental.

5. There needs to be a change in the idea as to where inquiry, at its most fundamental, is located. It is not esoteric theoretical physics, but rather the thinking we engage in as we seek to achieve what is of value in life. Academic thought is a (vital) adjunct to what really matters, personal and social thought active in life.

6. There needs to be a dramatic change in the nature of social inquiry (reflecting points 1 to 5 ). Economics, politics, sociology, and so on are not, fundamentally, sciences, and do not, fundamentally, have the task of improving knowledge about social phenomena. Instead, their task is threefold. First, it is to articulate problems of living, and propose and critically assess possible solutions, possible actions or policies, from the standpoint of their capacity, if implemented, to promote wiser ways of living. Second, it is to promote such cooperatively rational tackling of problems of living throughout the social world. And third, at a more basic and long-term level, it is to help build the hierarchical structure of aims and methods of aim-oriented rationality into personal, institutional, and global life, thus creating frameworks within which progressive improvement of personal and social life aims-and-methods becomes possible. These three tasks are undertaken in order to promote cooperative tackling of problems of living-but also in order to enhance empathic or "personalistic" understanding between people as something of value in its own right. Acquiring knowledge of social phenomena is a vital but subordinate activity, engaged in to facilitate the above three fundamental pursuits.

7. Natural science needs to change, so that it includes at least three levels of discussion: evidence, theory, and research aims. Discussion of aims needs to bring together scientific, metaphysical, and evaluative consideration in an attempt to discover the most desirable and realizable research aims. It needs to influence, and be influenced by, exploration of problems of living undertaken by social inquiry and the humanities, and the public.

8. There needs to be a dramatic change in the relationship between social inquiry and natural science, so that social inquiry becomes intellectually more fundamental from the standpoint of tackling problems of living, promoting wisdom. Social inquiry influences choice of research aims for the natural and technological sciences, 
and is, of course, in turn influenced by the results of such research. (Social inquiry also, of course, conducts empirical research, in order to improve our understanding of what our problems of living are and in order to assess policy ideas whenever possible.)

9. The current emphasis on specialized research needs to change so that sustained discussion and tackling of broad, global problems that cut across academic specialities is included, both influencing and being influenced by specialized research.

10. Academia needs to include sustained imaginative and critical exploration of possible futures, for each country, and for humanity as a whole, policy and research implications being discussed as well.

11. The way in which academic inquiry as a whole is related to the rest of the human world needs to change dramatically. Instead of being intellectually dissociated from the rest of society, academic inquiry needs to be communicating with, learning from, teaching and arguing with the rest of society - in such a way as to promote cooperative rationality and social wisdom. Academia needs to have just sufficient power to retain its independence from the pressures of government, industry, the military, and public opinion, but no more. Academia becomes a kind of civil service for the public, doing openly and independently what actual civil services are supposed to do in secret for governments.

12. There needs to be a change in the role that political and religious ideas, works of art, expressions of feelings, desires and values have within rational inquiry. Instead of being excluded, they need to be explicitly included and critically assessed, as possible indications and revelations of what is of value, and as unmasking of fraudulent values in satire and parody, vital ingredients of wisdom.

13. There need to be changes in education so that, for example, seminars devoted to the cooperative, imaginative, and critical discussion of problems of living are at the heart of all education from five-year-olds onwards. Politics, which cannot be taught by knowledge-inquiry, becomes central to wisdom-inquiry, political creeds and actions being subjected to imaginative and critical scrutiny.

14. There need to be changes in the aims, priorities, and character of pure science and scholarship, so that it is the curiosity, the seeing and searching, the knowing and understanding of individual persons that ultimately matters, the more impersonal, esoteric, purely intellectual aspects of science and scholarship being means to this end. Social 
inquiry needs to give intellectual priority to helping empathic understanding between people to flourish (as indicated in 6 above).

15. There need to be changes in the way mathematics is understood, pursued and taught. Mathematics is not a branch of knowledge at all. Rather, it is concerned to explore problematic possibilities, and to develop, systematize, and unify problem-solving methods. ${ }^{20}$

16. Literature needs to be put close to the heart of rational inquiry, in that it explores imaginatively our most profound problems of living and aids personalistic understanding in life by enhancing our ability to enter imaginatively into the problems and lives of others.

17. Philosophy needs to change so that it ceases to be just another specialized discipline and becomes instead that aspect of inquiry as a whole that is concerned with our most general and fundamental problemsthose problems that cut across all disciplinary boundaries. Philosophy needs to become again what it was for Socrates: the attempt to devote reason to the growth of wisdom in life.

18. Academic contributions need to be written in as simple, lucid, jargon-free a way as possible, so that academic work is as accessible as possible across specialities and to non-academics.

19. There needs to be a change in views about what constitute academic contributions, so that publications which promote (or have the potential to promote) public understanding as to what our problems of livings are and what we need to do about them are included, in addition to contributions addressed primarily to the academic community.

20. Every university needs to create a seminar or symposium devoted to the sustained discussion of fundamental problems that cut across all conventional academic boundaries, global problems of living being included as well as global problems of knowledge and understanding.

The above changes all come from my "from knowledge to wisdom" argument spelled out above, and in detail elsewhere. The following three institutional innovations do not follow from that argument but, if implemented, would help wisdom-inquiry to flourish.

21. Natural science needs to create committees, in the public eye, and manned by scientists and nonscientists alike, concerned to highlight and discuss failures of the priorities of research to respond to the interests of those whose needs are the greatest - the poor of the

20 See Nicholas Maxwell, "Wisdom Mathematics," Friends of Wisdom Newsletter 6 (2010): 1-6. http://www.ucl.ac.uk/friends-of-wisdom/newsletter. 
Earth-as a result of the inevitable tendency of research priorities to reflect the interests of those who pay for science, and the interests of scientists themselves.

22. Every national university system needs to include a national shadow government, seeking to do, virtually, free of the constraints of power, what the actual national government ought to be doing. The hope would be that virtual and actual governments would learn from each other.

23. The world's universities need to include a virtual world government which seeks to do what an actual elected world government ought to do, if it existed. The virtual world government would also have the task of working out how an actual democratically elected world government might be created.

\section{References}

Biddington, Terry. "Review: In Praise of Natural Philosophy." Metapsychology 21 (2017):

34. http://metapsychology.mentalhelp.net/poc/view_doc.php?type=book\&id= $7935 \& \mathrm{cn}=394$.

Chakravartty, Anjan. “Review.” Times Higher Education Supplement (1999): 24.

Davidow, Joseph. “Review.” Learning for Democracy 2 (2006): 78-80.

Dixon, Norman Frank. Our Own Worst Enemy. London: Futura, 1988.

Easlea, Brian. “Review.” Journal of Applied Philosophy 3 (1986): 139-40.

Farganis, James, ed. Readings in Social Theory: The Classic Tradition to Post-Modernism.

New York: McGraw-Hill, 1993.

Gay, Peter. The Enlightenment: An Interpretation. London: Wildwood House, 1973.

Grebowicz, Margret. “Review.” Metascience 15 (2006): 141-44.

Harris, Marvin. Cultural Materialism. London: Vintage, 2001.

Hayek, Friedrich August. The Counter-Revolution of Science. Indianapolis, IN: Liberty Press, 1979.

Hendry, John. "Review." British Journal for the History of Science 22 (1989): 246-47.

Iredale, Mathew. "Review." The Philosopher's Magazine 31 (2005): 86-87.

Israel, Jonathan. Democratic Enlightenment. Oxford: Oxford University Press, 2013.

Kneller, George F. Science as a Human Endeavor. New York: Columbia University Press, 1978.

Koertge, Noretta. "Review." Isis 80, no. 1 (1989): 146-47.

Longuet-Higgins, Christopher. "For Goodness Sake.” Nature 312 (1984): 204.

Lorimer, David. “Aim-Oriented Empiricism.” Paradigm Explorer 2017, no. 2 (2017): 43-44.

MacIntyre, Alisdair. "The Very Idea of a University." British Journal of Educational Studies 57, no. 4 (2009): 358. 
Maxwell, Nicholas. What's Wrong with Science? Towards a People's Rational Science of Delight and Compassion. Hayes: Bran's Head Books, 1976. . "Science, Reason, Knowledge and Wisdom: A Critique of Specialism." Inquiry 23 (1980): 19-81. From Knowledge to Wisdom: A Revolution in the Aims and Methods of Science. Oxford: Basil Blackwell, 1984. . "What Kind of Inquiry Can Best Help Us Create a Good World?" Science, Technology and Human Values 17 (1992): 205-27.

The Comprehensibility of the Universe: A New Conception of Science. Oxford: Oxford University Press, 1998.

. "Can Humanity Learn to become Civilized? The Crisis of Science without Civilization." Journal of Applied Philosophy 17 (2000): 29-44. Is Science Neurotic? London: Imperial College Press, 2004. From Knowledge to Wisdom: A Revolution for Science and the Humanities. London: Pentire Press, 2007 (2nd revised and extended edition). "From Knowledge to Wisdom: The Need for an Academic Revolution." London Review of Education 5, no. 2 (2007): 97-115.

. Cutting God in Half-And Putting the Pieces Together Again: A New Approach to Philosophy. London: Pentire Press, 2010a.

"Wisdom Mathematics." Friends of Wisdom Newsletter 6 (2010): 1-6. http:// www.ucl.ac.uk/friends-of-wisdom/newsletter.

"Arguing for Wisdom in the University: An Intellectual Autobiography." Philosophia 40, no. 4 (2012): 663-704.

. How Universities Can Help Create a Wiser World: The Urgent Need for an Academia Revolution. Exeter: Imprint Academic, 2014.

In Praise of Natural Philosophy: A Revolution for Thought and Life. Montreal: McGill-Queen's University Press, 2017. . Karl Popper, Science and Enlightenment. London: UCL Press, 2017. . Understanding Scientific Progress. Saint Paul, MN: Paragon House, 2017. "Can Universities Save Us from Disaster?" On the Horizon, 25, no. 2 (2017): 115-30. http://www.emeraldinsight.com/doi/full/10.1108/OTH-04-2016$\underline{0019}$.

Two Great Problems of Learning: Science and Civilization. https://philpapers. org/rec/MAXTGP-2.

McHenry, Leemon. "Review." Review of Metaphysics 59, no. 3 (2006): 657-59.

McHenry, Leemon, and Jon Jureidini. "Industry-sponsored Ghostwriting in Clinical Trial Reporting: A Case Study." Accountability in Research: Policies and Quality Assurance 15 , no. 3 (2008): 152-67.

Midgley, Mary. “Is Wisdom Forgotten?" University Quarterly: Culture, Education and Society 40 (1986): 425-27.

Muller, Fred. "Maxwell's Lonely War." Studies in History and Philosophy of Modern Physics 35 (2004): 109-10 and 117. 
Müürsepp, Peeter. “Review.” Dialogue and Universalism 2 (2014): 247.

Richards, Stewart. "Philosophical Aspects of Science." Annals of Science 42 (1985): 34849.

Roush, Sherrilyn. "Review." The Philosophical Review 110 (2001): 85-87.

Sardar, Ziauddin. "Lies, Damn Lies ... And a Way of Getting Out of Them." Afkar: Inquiry 2 (8) (1985): 66-67.

Shanks, Niall. "Review." Metascience 9 (2000): 294-98.

Smart, John Jamieson Carswell. "Review." British Journal for the Philosophy of Science 51 (2000): 907-11.

Stanley, Donald. “Review of Is Science Neurotic?” Metapsychology 1 1, no. 30 (2007). http:// metapsychology.mentalhelp.net/poc/view_doc.php?type=book\&id=3746\&cn=394. 